\title{
Glukoz 6 Fosfat Dehidrogenaz (G6PD) Eksikliğine Bağlı Hemolitik Anemi
}

\author{
Hemolytic Anemia Due To Glucose-6-Phosphate Dehydrogenase (G6PD) Defect
}

\section{Mehmet Fatih Orhan}

Sakarya Üniversitesi Tip Fakültesi Eğitim ve Araştırma Hastanesi, Çocuk Hematolojisi ve Onkolojisi Bilim Dalı, 54100 Adapazarı/Sakarya

\author{
Yazışa Adresi / Correspondence: \\ Mehmet Fatih Orhan \\ Sakarya Üniversitesi Tip Fakültesi, İç Hastalıkları ABD, Gastroenteroloji Kliniği 54290 Korucuk, Sakarya, Türkiye \\ T: + $902648884000 \quad$ E-mail: forhan@sakarya.edu.tr \\ Geliş Tarihi / Received : 08.08.2020 Kabul Tarihi / Accepted : 18.06.2021 \\ Orcid: \\ Mehmet Fatih Orhan https://orcid.org/0000-0001-8081-6760 \\ (Sakarya Tip Dergisi / Sakarya Med J 2021, 11(3):727-733 ) DoI: 10.31832/smj.778283
}

$\ddot{O} z$

Glukoz-6-fosfat dehidrogenaz (G6PD) eksikliği, dünya capında 500 milyon insanı etkileyen en yaygın kalısal kırmızı kan hücresi (RBC) enzimatik kusurudur. G6PD eksikliğ̈, X'e bağı̆ bir hastalıktır. Erkeklerin etkilenme olasllı̆̆ı daha yüksektir ve heterozigot kadınlar tipik olarak etkilenmeyen taşıyıcclardır. Ancak homozigot, bileşik heterozigot veya X inaktivasyonuna sahip heterozigot olan kadıllar klinik olarak anlamlı hemolize neden olabilir. En yaygın G6PD varyantları Akdeniz ülkelerinde (Akdeniz tipi), Afrika'nın bazı kısımlarında (Afrika tipi; G6PD A) ve Hindistan ile Güney Doŏu Asya'nın bazı bölgelerindedir. Akut hemoliz ortamında bireylerde yanlıs negatif sonuçlar ortaya çıkabilir, çünkü en ciddi G6PD eksikliği olan hücreler yok edilmiştir. Bu gibi durumlarda testler, hemolitik atak iyileștikten üç ay sonra tekrarlanmalıdr. G6PD eksikliğinin teşhisi ve yönetimi; çocuk doktoru, iç hastalıkları uzmanı, genetik uzmanı, laboratuvar uzmanı, çocuk hemşireleri ve hematolog tan oluşan bir ekiple yapılabilir. Tedavi öncelikle genel klinik tabloya bağldır. Destekleyici bakım ve indükleyici ajanların kesilmesi ve önlenmesi ile yönetilebilir.

Anahtar Glukoz-6-Fosfat Dehidrogenaz; Hemolitik Anemi; Bakla; Favizm; Oksidatif Stres

Kelimeler

Glucose-6-phosphate dehydrogenase (G6PD) deficiency; is the enzyme deficiency of erythrocytes affecting 500 million people globally. It is a genetic disease that inherits the $X$ chromosome. Therefore, while men are more frequently affected, heterozygous women are usually unaffected carriers. However, women who are homozygous, compound heterozygous, or heterozygous with $X$ inactivation can cause clinically significant hemolysis. The most common G6PD variants are in Mediterranean countries, parts of Africa, and India and South-East Asia. In the case of acute hemolysis, false-negative results may occur in individuals because the cells with the most severe G6PD deficiency have been destroyed. In such cases, the tests should be repeated three months after the hemolytic attack. Diagnosis and management of G6PD deficiency; Pediatrician, internal medicine specialist, geneticist, laboratory specialist, pediatric nurses and haematologist. Treatment primarily depends on the general clinical picture. It can be managed by supportive care and interruption and prevention of inducing agents.

Keywords Glucose-6-Phosphate Dehydrogenase; Hemolytic Anemia; Fava Bean; Favism; Oxidative Stress 


\section{GíRìş}

Hemolitik anemi, alyuvarların normal ömürlerini tamamlamadan yıkıma uğrayarak kan dolaşımından uzaklaşması durumudur. Hemolitik anemilerin pek çok nedeni vardır. $\mathrm{Bu}$ durumlar kalıtsal ya da edinsel olabilir. Kalıtsal olanların sık nedenlerinden biri Glukoz-6-fosfat dehidrogenaz (G6PD) eksikliği olup, NADPH üreten ve eritrositleri oksidatif hasardan koruyan G6PD'de genetik bir kusurun neden olduğu kalıtsal bir hastalıktır. G6PD eksikliği, eritrositlerin en yaygın enzimatik bozukluğudur. Enzim tüm hücrelerde bulunmasına rağmen, eritrositler bu eksiklikten en çok etkilenen hücrelerdir.

Eritrositlerin normal yaşamlarını devam ettirebilmek için enerjiye gereksinimleri vardır. Eritrositlerde mitokondri bulunmadığından, gerekli enerjiyi Embden Meyerhof yolu denilen anaerobik glikolizden elde ederler. Eritrositlerin yaşamlarını sürdürmeleri için enerji gereksinimlerini karşılamalarına ek olarak, hemoglobin ve hücredeki proteinleri oksidan etkilerden korumaları gerekir. Eritrositlerde pentoz monofosfat yolunda bulunan G6PD enzimi, hücreyi oksidan hasardan korumak amacıyla görev yapar. ${ }^{1}$ G6PD, nikotinamid adenin dinükleotid fosfatı (NADP) indirgenmiş formuna (NADPH) dönüştürmek için glukoz-6-fosfat kullanan pentoz fosfat yolunun hiz sınırlayıcı ilk aşamasında katalizördür. ${ }^{2}$

Hemolitik aneminin şiddeti, G6PD eksikliği olan kişiler arasında değişir. Güvenli ve güvenli olmayan ilaçlar ve gıdalarla ilgili hasta eğitimi, hemoliz ataklarını önlemek için önemlidir. Eritrosit enzimopatileri heterojen bir grup olup, sebebi belirlenemeyen kronik hemolitik anemilerde veya herhangi bir oksidan ilaç alımı sonrası gelişen akut hemoliz olaylarında düşünülmesi gereken hastalıklardan biridir.

\section{Epidemiyoloji}

Dünyadaki en yaygın enzimopati olma özelliğini gösteren G6PD enzim eksikliği, hemoglobinopatilerden sonra ikinci sıklıkta görülen kalıtsal bir hastalıktır. G6PD eksikliği; dünya çapında 500 milyon kişiyi etkileyen eritrositlerin en sık görülen enzimatik bozukluğudur. ${ }^{3}$ İlk olarak 1950’nin başlarında, Amerikalı zencilerde antimalaryal ilaçların araştırılması sırasında ortaya çıkan hemolitik tablolar ile G6PD yetmezliği tanımlanmış ve daha sonra ilerleyen çalışmalarla Akdeniz yöresinde yaygın olarak bulunduğu tespit edilmiştir. Enzim yetmezliğinin en sık görüldüğü bölgeler, ekvatoryal kuşakta bulunan tropikal nitelikli bölgelerdir. En fazla Afrika'da (\%20) olmakla birlikte Akdeniz (\%4-30) ve Güneydoğu Asya’da yaygındır. ${ }^{4}$ Bu gezegendeki coğrafik dağılım, sıtmanın bir zamanlar endemik olduğu bölgelerle yüksek oranda ilişkilidir. Bu dağılım da G6PD eksikliğinin, Plasmodium falciparum enfeksiyonuna karşı seçici bir avantaj sağlayabileceği hipotezine yol açmıştır. ${ }^{3}$ İlginç bir şekilde, G6PD eksikliğinin komplikasyonsuz sitmaya karşı koruyucu olduğunu, ancak ciddi sıtma vakalarına karşı koruyucu olmadığını gösteren kanıtlar vardır. ${ }^{2}$

\section{Sinıflama}

Dünya Sağlık Örgütü tarafından enzim eksikliğinin büyüklügüne ve hemolizin şiddetine göre sınıflandırılmıştır. ${ }^{5}$ Bu sınıflandırma, kişinin oksidatif strese maruz kaldığında olabilecek hemolizin ciddiyeti konusunda fikir verir. Sinıf I, II ve III klinik öneme sahip iken diğerleri klinik olarak önemli değildir (Tablo 1).

\begin{tabular}{|l|l|}
\hline \multicolumn{2}{|l|}{ Tablo 1. G6PD Varyantlarına göre WHO Sınıflaması } \\
\hline SINIFLANDIRMA & G6PD $^{1}$ VARYANTLARI \\
\hline Sınıf I & $\begin{array}{l}\text { Normal aktivitenin \%1'inden az/saptanama- } \\
\text { yan ciddi enzim eksikliği, kronik hemoliz }\end{array}$ \\
\hline Sınıf II & $\begin{array}{l}<\% 10 \text { aktiviteye sahip şiddetli enzim ek- } \\
\text { sikliği, aralıklı hemoliz; ilaç kaynaklı }\end{array}$ \\
\hline Sınıf III & $\begin{array}{l}\% 10-60 \text { aktivite ile hafif ila orta dereceli } \\
\text { enzim eksikliği, aralıklı hemoliz ortaya çıkar }\end{array}$ \\
\hline Sınıf IV & $\begin{array}{l}\text { Klinik problem olmaksızın \%60-90 aktivite } \\
\text { ile çok hafif enzim eksikliği }\end{array}$ \\
\hline Sınıf V & $\begin{array}{l}\text { Klinik problem olmadan> \%110 aktivite ile } \\
\text { çok hafif enzim eksikliği }\end{array}$ \\
\hline${ }^{1}$ Glukoz 6 Fosfat Dehidrogenaz \\
\hline
\end{tabular}




\section{Cinsiyetin Önemi}

Genetik olarak G6PD eksikliği, X’e bağlı bir hastalıktır. G6PD geni, X kromozomunun uzun kolu üzerinde Xq28 bölgesinde lokalizedir. Bilinen 217 mutasyonu vardır. ${ }^{6} \mathrm{Ve}$ bunların yaklaşık yarısı sporadiktir. ${ }^{3} \mathrm{G} 6 \mathrm{PD}$ gen anomalilerinin en çok görüleni tek bir amino asit değişikliğine neden olan nokta mutasyonlarıdır. X’e bağlı olarak, erkekler hemizigot normal veya hemizigot hasta olabilirken, dişiler homozigot normal, homozigot hasta veya heterozigot olabilir. ${ }^{1}$ G6PD mutasyonu taşıyan erkekler bu hastalık için hemizigottur; tüm eritrositleri etkilenir. Heterozigot bir G6PD mutasyonu taşıyan kadınlar ise genellikle ciddi hemolitik anemi yaşamazlar. Çünkü eritrositlerinin yarısı normal G6PD içermektedir. X-inaktivasyonu veya birleşik heterozigot olduğunda problem yaşayabilirler. Bu kadınlar, erkekler gibi ciddi oranda etkilenebilir. Bir çalışmada, çocuk doktorlarının çoğunun G6PD eksikliğinin sadece erkek bir hastalık olduğunu düşündüğünü göstermekte ve bu nedenle, bazı kadın hastalara tanı konmamış olabileceği vurgulanmıştır. ${ }^{7}$ Bu yüzden X’e bağlı resesif geçiş gösteren hastalıkların geçiş paterni iyi bilinmelidir. ${ }^{8}$

\section{Semptomlar}

- Cilt ve mukozalarda sarilık

- Koyu sar1-turuncu idrar

- Solukluk, yorgunluk

- Hizlı nefes alma

- Zayıf ve hızlı nabız

\section{Klinik Bulgular}

Yenidoğan Sarılığı: G6PD eksikliğinin klinik olarak en önemli komplikasyonlarından biri, doğumdan 2-3 gün sonra zirve yapan yenidoğan sarılığıdır. ${ }^{1}$ Yeni doğan bebeklerin G6PD eksikliğinde, doğumun ilk günlerinde karaciğer fonksiyonlarının tam çalışır düzeyde olmaması ve ciddi enzim eksikliği nedeniyle bilirubin yeterli hızda metabolize edilemez, böylece sarılığa yol açar. G6PD eksikliği olan yenidoğanların genel nüfusa göre hiperbilirubinemi gelişme olasılığı iki kat daha fazladır ve kernikterus vakalarının yaklaşık \% 20’si G6PD eksikliği ile ilişkilidir. ${ }^{2}$ Em- ziren annelerin bakla yemesi sonrasında G6PD eksikliği olan bebeklerinde de hemoliz bildirilmiştir.

Kernikterus: Yenidoğan eritrositlerinin, glutatyon peroksidaz, katalaz ve vitamin eksikliği sonucu olarak ortaya çıkan oksidatif stresle başa çıkma kapasiteleri düşük olduğundan, hemolitik anemi oluşma riski, yetişkinlerden daha fazladır. Anemi ve sarılık; ilk olarak ciddi G6PD eksikliği olan bireylerde (Sınıf I varyantları) yenidoğan döneminde sıklıkla görülür. Sarılık derecesi oldukça değişkendir. Sınıf II veya III G6PD eksikliği olan yenidoğanlarda sarllık nadiren doğumda bulunur; başlangıçtaki zirve doğumdan 2-3 gün sonrasındadır. Ağır vakalarda, hasta agresif olarak tedavi edilmezse bilirubin kaynaklı nörolojik disfonksiyon ve kernikterus riski vardır. ${ }^{9}$ Kanda yükselen bilirubin kan beyin bariyerini geçerek beynin bazı çekirdeklerine zarar verir, çocukta zeka geriliği ve serebral palsiye neden olabilir. $^{10}$

\section{Kronik Hemoliz}

Şiddetli hastalığ (Sınıf I varyant) olan nadir kişilerde kronik hemoliz görülür. Enzim eksikliğinin derecesine bağlidir.

\section{Bakla}

Bazı yiyecekler, G6PD eksikliği olan kişilerde hemoliz ataklarını tetikleyebilir. Baklanın yenmesi klasik örnektir. Baklanın adı değişik dillerde farklı kelimelerle ifade edildir. (Tablo 2). ${ }^{19}$ En sık 1-5 yaş arasındaki erkek çocuklarda görülür. Semptomlar, bakla yendikten 5-24 saat sonra başlar. Baş ağrısı, bulantı, sırt ağrısı, titreme ve ateş çıkabilir. Bunu hemoglobinüri ve sarllık takip eder. ${ }^{11}$ Hemoglobin konsantrasyonundaki düşüş akut ve genellikle transfüzyon gerektirecek kadar şiddetlidir. Fava fasülyesi polenlerinin solunması ya da süt veren annenin bakla yemesi de bebekte klinik bulgulara neden olabilir. Bir Ortadoğu yemeği olan falafel'in güvenliği de içeriği ile ilgilidir. Bazı yerlerde fava fasulyesinden yapılırken, başka yerlerde G6PD eksikliği olan insanlar için güvenli kabul edilen nohuttan yapılır. 


\begin{tabular}{|l|l|l|l|}
\hline \multicolumn{4}{|l}{ Tablo 2. Bakla’nn diğer dillerdeki isimleri } \\
\hline Almanca & Favabohnen & İtalyanca & Fava \\
\hline Arapça & Foolle & Katalanca & Fava \\
\hline Çince & Tzan-Doo & Kürtçe & Paqla \\
\hline Farsça & Ba-ghe-Leh & Macarca & Lóbab \\
\hline Felemenkçe & Tuinboon & Malaya Dili & Kacang Parang \\
\hline Fransızca & Fève & Tai Dili & two-ah pak-ah \\
\hline İbranice & Polle & Türkçe & Bakla \\
\hline İngilizce & $\begin{array}{l}\text { Fava/Broad } \\
\text { Bean }\end{array}$ & Urduca & $\begin{array}{l}\text { Lobhiya, Rajma, } \\
\text { Jheam }\end{array}$ \\
\hline İspanyolca & Haba & Yunanca & Koukia \\
\hline
\end{tabular}

\section{İlaç}

Çoğu asemptomatiktir ve uyaran yok iken hemoliz yoktur. Hemolizin şiddeti ve potansiyel klinik komplikasyonları anemi ile kabaca orantılıdır. G6PD eksikliği olan bazı kişilerde; ilaçlar, akut hastalıklar ve bazı gıdalardan sonra oksidan hasar ortaya çıkar. Bunun sonucunda akut hemoliz atakları görülür. G6PD Afrika tipinde ilaç devam etse bile, $\mathrm{Hb}$ düzelme eğilimine girer. G6PD Akdenizli bireylerde anemi daha şiddetlidir, çünkü dolaşımdaki eritrositler hemolize karşı savunmasızdır. Bu bireylerde hemoliz, ilaç kesildikten sonra bile devam edebilir. COVID-19 pandemisinde daha sık kullanmaya başladığımız klorokin ve hidroksiklorokin normal terapotik dozlarda kullanıldığında muhtemelen güvenlidir. RBC ömrünü hafifçe kısaltan ilaçlar gibi bazı ilaçlar hakkında çelişkili bilgiler bulunabilir. Bunlar bazı listelerde "güvenli", bazılarında "güvensiz" olarak görünebilir. ${ }^{12}$ COVID-19 enfeksiyonunu tedavi etmek için kullanılabilecek bazı ilaçlar G6PD eksikliği olan bireylerde hemolitik krize neden olabilir, bu açıdan tarama yapmak da gerekli olabilir. ${ }^{13-16}$

\section{Kına ve Naftalin}

Saç boyaları ve dövmelerde kullanılan kına bileşikleri ${ }^{17,18}$ ve naftalin (güve topları ve lavabo deodorantlarında bulunan) gibi kimyasallar da hemolize neden olabilir. Avrupa Birliği’nde naftalin içeren ürünler, 2008'den sonra yasaklandığ 1 için artık daha az yaygındır. ${ }^{1}$

\section{Enfeksiyon}

Hemoliz mekanizması iyi tanımlanmamış olmasına rağmen, bakteriyel ve viral enfeksiyonlar G6PD eksikliği olan bireylerde akut hemolitik anemi tetikleyicileri olarak bilinir. Reaktif oksijen türlerinin (ROS) birçok enfeksiyonun patogenezinde rol oynadığ 1 ve bunların oksidatif hasara neden olduğu bilinmektedir. ${ }^{1}$ Enfeksiyon sırasında G6PD eksikliği olan eritrositlerin hızla yıkılmasından sorumlu faktörler bilinmemektedir.

\section{Tanı}

İlaç veya gıda alımından 2-4 gün sonra, hemoglobin konsantrasyonunda 3-4 g/dL arasında ani bir düşüşle birlikte sarılık, solukluk ve koyu idrar vardır. Periferik kan yaymasinda: mikrosferositler, bite hücreleri ve blister hücreleri görülebilir. ${ }^{11}$ Hemoliz hem ekstravasküler hem de intravaskülerdir. Anemi, eritropoez stimülasyonunu indükler. $\mathrm{Bu}$ retikülositler ve daha genç eritrositler, yüksek G6PD aktivitesine sahiptir.

En yaygın tarama yöntemi, NADP'den NADPH oluşumunu tespit etmek için hızlı bir floresan nokta testi içerir. ${ }^{2}$ Tarama, ayrıca nicel bir spektrofotometrik analizle de gerçekleștirilebilir. G6PD enzim düzeyi testi şu durumlarda istenebilir: ${ }^{1}$

- Bazı antimalaryal veya diğer "oksidan" ilaçlarla tedaviden önce

- Yenidoğanda hemolitik anemi (immün olmayan)

- Uzun süren veya şiddetli olan yenidoğan sarıllı̆̆

- Oksidan" ilaçlarla veya enfeksiyon ilişkili hemoliz

- Favizm

- Erkeklerde ve kadınlarda konjenital non-sferositik hemolitik anemi

- Hemoglobinüri

- Orak hücre hastalığ1

- Talasemik hastalıklar

- Ailede G6PD eksikliği öyküsü

- Lösemi, lenfoma veya diğer maligniteleri olanlarda rasburikaza ihtiyacı duyan hastalar

- Donör G6PD eksikliği veya durumu bilinmiyor iken 
hematopoetik kök hücre nakli sonrasında görülen akut hemoliz

Akut hemolitik atak durumunda, azalmış G6PD aktivitesine sahip olan eritrositler hemoliz olacaktır ve bu nedenle G6PD testi sağlam kalan eritrositlerin düzeyini ölçecektir. Bu durumda eksiklik olmasına rağmen, G6PD düzeyi normal çıkacaktır. Bu nedenle, ilk test normalse ve G6PD eksikliği şüphesi devam ediyorsa, test hemolitik atak geçtikten yaklaşık üç ay sonra tekrarlanmalıdır. O zaman yeni üretilen eritrositlerin düzeyi ölçülmüş olacak ve daha doğru bir fikir verecektir. Sonuçlar, hemoglobin gramı başına enzim aktivitesi birimleri olarak ifade edilir. Normal aralıklar kullanılan yönteme ve test sıcaklığına bağlı olarak değişebilir.

- $\quad 25^{\circ}$ C'de tipik normal aralık: 5.5 ila 8.8 birim / gram hemoglobin

- $\quad 37^{\circ}$ C'de tipik normal aralık: 8.0 ila 13.5 ünite / gram hemoglobin

G6PD düzeyleri yenidoğanda, erişkinlere göre daha yüksektir. Laboratuvar çalışmaları; tam kan sayımı, bilirubin seviyeleri, retikülosit sayımı, serum aminotransferazlar ve laktat dehidrojenazı içerir. Periferik kan yayması, şistositler gibi hemoliz belirtileri gösterebilir. ${ }^{2}$ G6PD eksikliği ile ilişkili hemolitik anemide, diğer hemolitik anemilerde olduğu gibi, artan eritrosit turnoveri nedeniyle HbAlc seviyesi yanlış bir şekilde düşük ölçülebilir. Diyabet hastası olan kişilerde bu göz önüne alınmalıdır.

\section{Ayırıcı Tanı}

G6PD eksikliğinin ayırıcı tanısı; hemolitik aneminin ve yenidoğan sarılığının diğer nedenlerini içerir:

- Otoimmün hemolitik anemi

- Bilirubin konjugasyon bozuklukları (örn. Gilbert sendromu $)^{19}$

- Yenidoğanın hemolitik hastalığı

- Herediter sferositoz

- Orak hücre anemisi

- Talasemi

\section{Tedavi}

G6PD eksikliğinin yönetiminin temel amac1, eritrositlere oksidatif stresin önlenmesidir.

G6PD eksikliğine bağlı yenidoğan sarılığı tedavisi, diğer nedenlerden kaynaklanan yenidoğan sarılığı için önerilenlerden farklı değildir. Yenidoğanlarda tedavi, sarılık tedavisine ve kernikterusu önlemeye odaklanır. ${ }^{20}$ Bunun için erken taburculuklarda aile eğitimi ihmal edilmemelidir. ${ }^{21}$ Kronik hemolizli bireyler için günde $1 \mathrm{mg}$ folik asit takviyesi yapmak gereklidir.

Enfeksiyon var ise tedavi edilmelidir. Daha ciddi vakalarda transfüzyon gerekebilir. ${ }^{2}$

G6PD eksikliği olan bireylerde hemolizi azaltmak için temel müdahale, hemolizi tetiklediği bilinen ilaçlara maruz kalmaktan kaçınmaktır. Tümör lizis sendromu için rasburikaz uygulanması gibi hayati ilaçlar verilmek zorunda kalındığında hemoliz yakın takip edilmelidir. COVID-19 hastalığının tedavisinde klorokin ve hidroksiklorokin kullanılmaktadır. Bu ilaçların her ikisi de G6PD eksikliğinde "kaçınılması gereken ilaçlar" listesinde yer almıştır. Bununla birlikte, birçok uzman bu ilaçların normal terapotik dozlarda kullanıldığında muhtemelen güvenli olduğunu düşünmektedir. ${ }^{12}$

Bağışlanan kan; G6PD eksikliği açısından taranmaz. G6PD eksikliği olan kişiler, anemisi olmadığı sürece kan bağışı yapabilirler. Bunun nedeni, transfüze edilen G6PD eksikliği olan eritrositlerin tipik ömrünün nispeten normal olduğunun düşünülmesidir.

\section{Etik Kurul Onayı}

Derleme olduğu için Etik Kurul onayına gerek yoktur.

\section{Çıkar Çatışması}

Yazarın herhangi bir çıkara dayalı ilişkisi yoktur. 


\section{Yazar Katkıları}

Fikir- MFO; Denetim- MFO; Yazıyı yazan - MFO.

\section{Akran gözlem ve değerlendirme}

Akran gözlemi ve değerlendirmesi harici olarak yapıldı. 
Sakarya Tip Dergisi 2021;11(3):727-733

ORHAN, Glukoz 6 Fosfat Dehidrogenaz (G6PD) Eksikliğine Bağlı Hemolitik Anemi

Kaynaklar

1. Roper D, Layton M, Rees D, et al. Laboratory diagnosis of G6PD deficiency. A British Society for Haematology Guideline. Br J Haematol. 2020;189(1):24-38. doi:10.1111/bjh.16366

2. S. Russ Richardson; Gerald F. O'Malley. Glucose 6 Phosphate Dehydrogenase (G6PD) Deficiency - StatPearls NCBI Bookshelf. Treasure Island (FL); 2020. https://www.ncbi.nlm.nih.gov/books/NBK470315/.

3. Luzzatto L, Ally M, Notaro R. Glucose-6-Phosphate Dehydrogenase Deficiency. Blood. July 2020. doi:10.1182/ blood.2019000944

4. What is G6PD Deficiency. https://www.g6pd.org/en/G6PDDeficiency.aspx. Accessed July 26, 2020.

5. Glucose-6-phosphate dehydrogenase deficiency. WHO Working Group. Bull World Health Organ. 1989;67(6):601-611. http://www.ncbi.nlm.nih.gov/pubmed/2633878. Accessed July 26, 2020.

6. Martinez-Rosas V, Juárez-Cruz MV, Ramírez-Nava EJ, et al. Effects of single and double mutants in human glucose-6-phosphate dehydrogenase variants present in the Mexican population: Biochemical and structural analysis. Int J Mol Sci. 2020;21(8). doi:10.3390/ijms21082732

7. Albayrak C, Albayrak D. Red Cell Glucose 6-Phosphate Dehydrogenase Deficiency in the Northern Region of Turkey: Is G6PD Deficiency Exclusively a Male Disease? Pediatr Hematol Oncol. 2015;32(2):85-91. doi:10.3 109/08880018.2014.940074

8. X-linked recessive inheritance -Wikipedia. https://en.wikipedia.org/wiki/X-linked_recessive_inheritance. Accessed July 27, 2020.

9. Kilicdag H, Gökmen Z, Ozkiraz S, Gulcan H, Tarcan A. Is it accurate to separate glucose-6-phosphate dehydrogenase activity in neonatal hyperbilirubinemia as deficient and normal? Pediatr Neonatol. 2014;55(3):202207. doi:10.1016/j.pedneo.2013.10.006

10. Katar S. Glucose-6-phosphate dehydrogenase deficiency and kernicterus of South-East Anatolia. J Pediatr Hematol Oncol. 2007;29(5):284-286. doi:10.1097/MPH.0b013e31805180dc

11. Luzzatto L, Arese P. Favism and glucose-6-phosphate dehydrogenase deficiency. N Engl J Med. 2018;378(1):6071. doi:10.1056/NEJMra1708111

12. Youngster I, Arcavi L, Schechmaster R, et al. Medications and glucose-6-phosphate dehydrogenase deficiency: An evidence-based review. Drug Saf. 2010;33(9):713-726. doi:10.2165/11536520-000000000-00000
13. Jamerson BD, Haryadi TH, Bohannon A. Glucose-6-Phosphate Dehydrogenase Deficiency: An Actionable Risk Factor for Patients with COVID-19? Arch Med Res. 2020. doi:10.1016/j.arcmed.2020.06.006

14. Maillart E, Leemans $S$, Van Noten $H$, et al. A case report of serious haemolysis in a glucose-6-phosphate dehydrogenase-deficient COVID-19 patient receiving hydroxychloroquine. Infect Dis (Auckl). 2020;52(9). do i:10.1080/23744235.2020.1774644

15. Oymak Y, Karapinar TH, Devrim I. Why g6PD Deficiency Should Be Screened before COVID-19 Treatment with Hydroxychloroquine? J Pediatr Hematol Oncol. 2020. doi:10.1097/MPH.0000000000001864

16. Beauverd Y, Adam Y, Assouline B, Samii K. COVID-19 infection and treatment with hydroxychloroquine cause severe haemolysis crisis in a patient with glucose-6-phosphate dehydrogenase deficiency. Eur I Haematol. 2020. doi:10.1111/ejh. 13432

17. Katar S, Devecioglu C, Özbek MN, Ecer S. Henna causes life-threatening hyperbilirubinaemia in glucose-6-phosphate dehydrogenase deficiency. Clin Exp Dermatol. 2007;32(2):235-236. doi:10.1111/j.13652230.2006.02306.x

18. Kök AN, Ertekin M V., Ertekin V, Avci B. Henna (Lawsonia inermis Linn.) induced haemolytic anaemia in siblings. Int J Clin Pract. 2004;58(5):530-532. doi:10.1111/j.1368-5031.2004.00048.x

19. Öner R, Acar C, Öner C, et al. Chronic hemolytic anemia associated with glucose 6-phosphate dehydrogenase (Guadalajara)1159 C $\rightarrow T(387 \mathrm{Arg} \rightarrow C y s)$ deficiency associated with Gilbert syndrome in a Turkish patient. Pediatr Hematol Oncol. 2002;19(1):39-44. doi:10.1080/088800102753356176

20. Çelik HT, Günbey C, Ünal Ș, Gümrük F, Yurdakök M. Glucose-6-phosphate dehydrogenase deficiency in neonatal hyperbilirubinaemia: Hacettepe experbox drawings light down and leftence.J Paediatr Child Health 2013;49(5):399-402. doi:10.1111/jpc.12193

21. Bozkurt Ö, Yücesoy E, Oğuz B, Akinel Ö, Palali MF, Ataș N. Severe neonatal hyperbilirubinemia in the southeast region of turkey. Turkish J Med Sci. 2020;50(1):103-109. doi:10.3906/sag-1906-22 